\title{
Serisel Korelasyonun Toplam Zenit Gecikmesi Zaman Serilerinde Parametrik Olmayan Trend Belirleme Üzerindeki Etkisi
}

\author{
The Effect of Serial Correlation on Nonparametric Trend Determination at Zenith Total \\ Delay Time Series
}

\author{
Cansu BEȘEL ${ }^{*}$, a , Emine TANIR KAYIKÇI ${ }^{\mathrm{b}}$ \\ ${ }^{1}$ Karadeniz Teknik Üniversitesi, Mühendislik Fakültesi, Harita Mühendisliği Bölümü, 61080,Trabzon
}

• Geliş tarihi / Received: 23.04.2018 • Düzeltilerek geliş tarihi / Received in revised form: 17.07.2018 • Kabul tarihi / Accepted: 23.07 .2018

\begin{abstract}
$\ddot{O} \mathbf{z}$
GNSS gözlemlerinin analizinden elde edilen toplam zenit gecikmesi (ZTD) hava şartlarının belirlenmesinde önemli bir parametre olması sebebiyle GNSS tekniğinin iklimsel çalışmalarda da önemli bir yeri vardır. ZTD verilerinden oluşturulan zaman serilerinin trend analizi ile, uzun dönemlerde veride meydana gelen değişimler incelenebilmektedir. Bu çalışmada, Türkiye ve Avrupa'dan seçilen 10 adet IGS (Uluslararası GNSS Servisi) istasyonu için 1995-2010 yılları arasındaki ZTD ürünlerinin COST Aksiyonu ES1206, GNSS4SWEC (Advanced Global Navigation Satellite Systems Tropospheric Products for Monitoring Severe Weather Events and Climate) kapsamında yeniden kestirimi ile elde edilmiş (IGS Repro1) verileri kullanılarak oluşurulan zaman serilerindeki trend ve serisel korelasyon etkisi belirlenmeye çalışılmıştır. Trend analizinde parametrik olmayan yöntemlerden Mann-Kendall testi kullanılmıştır. Serisel korelasyonu belirlemek için otokorelasyon katsayısı hesaplanmış olup seriyi korelasyondan arındırmak için Trend-Free Prewhitening yöntemi uygulanmıştır. Korelasyondan arındırılan seriye tekrar trend analizi yapılarak serisel korelasyonun trendin belirlenmesi üzerindeki etkisi ve Trend-Free Prewhitening yönteminin performansı üzerine irdelemeler yapılmaya çalışılmıştır. Çalışmada IGS istasyonlarındaki ZTD verilerinin tümünde anlamlı serisel korelasyonlar elde edilmiştir. Aynı zamanda LAMA, ONSA ve PENC istasyonlarında Trend-Free Prewhitening uygulandıktan sonra trend olduğu sonucuna varılmıştır. Çalışma kapsamında uygulanan yöntemlerle ilgili hesaplamalar MATLAB program kodları kullanılarak yapılmıştır.
\end{abstract}

Anahtar kelimeler: Mann-Kendall Testi, Serisel Korelasyon, Trend, Trend-Free Prewhitening, Toplam Zenit Gecikmesi

\begin{abstract}
GNSS technique is important in climate studies because of obtaining Zenith Total Delay which is significant parameter to determine weather conditions with analysis of GNSS observations. Interchanges of long term data can be detected via trend analysis produced by ZTD time series data. In this study, trend and serial correlation effect of time series of (IGS Repro1) were investigated using between 1995-2010 reprocessed ZTD data in the framework of COST Action ES1206, GNSS4SWEC (Advanced Global Navigation Satellite Systems Tropospheric Products for Monitoring Severe Weather Events and Climate). Mann-Kendall test was performed for nonparametric method. The autocorrelation coefficient was calculated to set the serial correlation. Trend-Free Prewhitening method has been applied to eliminate the correlation. The effect on the trend determination of serial correlation and the performance of Trend-Free Prewhitening method were tried to made examination by making re-trend analysis in series which eliminated correlation. As a result of the performed methods, serial correlation is substantial whole ZTD data. At the same time, there are trends in LAMA, ONSA and PENC stations after applying Trend-Free Prewhitening. In this work, MATLAB programming language was handled in all of the tests.
\end{abstract}

Keywords: Mann-Kendall Test, Serial Correlation, Trend, Trend-Free Prewhitening, Zenith Total Delay

\footnotetext{
*a Cansu BEŞEL; cansubesel@ktu.edu.tr; Tel: (0462) 37727 76; orcid.org/0000-0003-3434-6483

${ }^{\mathrm{b}}$ orcid.org/0000-0001-8259-5543
} 


\section{Giriş}

İklim değişikliği, en önemli çevre sorunlarından biridir. Küresel Navigasyon Uydu Sistemi (GNSS) iklim çalışmalarında sağladığı avantajlar sebebiyle önemlidir. GNSS sinyalleri yer yüzündeki alıcılara ulaşmadan önce atmosferin yapısından kaynaklı olarak troposferik gecikmeye uğramaktadır. $\mathrm{Bu}$ gecikme, genellikle zenit doğrultusuna dönüştürülerek Toplam Zenit Gecikmesi (ZTD-Zenith Total Delay) olarak elde edilmektedir (Baldysz vd., 2016). ZTD verileri zamana bağlı sıcaklık ve su buharı içeriği ile korelasyon göstermektedir (Guerova, 2013; Yong vd., 2008). ZTD verilerinin büyüklügü ve mevsimsel değişkenliği enlem, boylam, su kütlesine uzaklık gibi etkenlere bağlıdır. $\mathrm{Bu}$ nedenle, ZTD verileri bölgesel hava şartları hakkında bilgi sağlamaktadır (Jin vd., 2007). ZTD'nin sıcaklık ve basınç gibi meteorolojik verilerle kullanılması ile su buharı belirlenebilmektedir (Bevis vd., 1992). İklim değişikliğini etkileyen en önemli faktörlerden biri olan su buhar1, sera gazı etkisine sebep olan temel gazlardan biridir ve atmosfer ve hidrolojik döngünün işleyişini şekillendirmede de önemli bir rol oynamaktadır (COST, 2012; Baldysz vd., 2015).

ZTD, Hidrostatik Zenit Gecikmesi (ZHD) olarak adlandırılan kuru bileşen ve Islak Zenit Gecikmesi (ZWD) olarak adlandırılan islak bileşenden oluşmaktadır. Islak gecikmeye atmosferik su buharı, kuru gecikmeye ise diğer tüm atmosferik bileşenler (büyük oranda sıcaklık ve basınç) sebep olur (Rocken vd., 1994). ZWD değişken bir yapıya sahip olduğundan sadece basınç, sıcaklık ve bağıl nem gibi yüzey ölçümleri (in-situ) ile doğru bir şekilde tahmin edilememektedir. ZWD; ZTD'nin \%10'unu oluşturmaktadır ve su buharının düzensiz dağılımından dolayı modellenmesi zordur. ZWD, ortalama atmosfer sicaklığ kullanarak entegre su buharına (Integrated Water Vapour-IWV) dönüştürülebilmektedir. $\mathrm{Bu}$ dönüşüm iklim çalışmalarında önemli bir yer tutmaktadır. ZTD verilerinden oluşturulan zaman serilerinin trend analizi ile, uzun dönemlerde veride meydana gelen değişimler göz önüne serilmektedir. Böylece, ZTD'nin su buharına bağlı sslak bileşeni olan ZWD etkisi tahmin edilebilmekte ve geleceğe yönelik meteorolojik yorumlar yapıla-bilmektedir (Tanır Kayıkçı ve Beşel 2017; Beşel 2017).

Zaman serileri, gözlemlenen trendlerin önemini büyük ölçüde etkileyen ve serisel bağımlılık olarak da bilinen otokorelasyon bileşenini içermektedir. Serisel bağımlılı̆̆ın giderilmesi, oldukça değişken zaman serilerinde zayıf trend eğilimlerinin belirlenmesinde önemlidir. Zaman serilerindeki otokorelasyon, trendin fazla veya eksik belirlenmesine sebep olmaktadır (Blain 2015).

Von Storch ve Navarra (1995), Hamed ve Rao (1998) ve Yue ve Wang (2002) yapmış oldukları çalışmalarda trend testinin performansını serisel korelasyonun varlığ durumda da test etmiştir. Çalışmaların sonucunda, pozitif serisel korelasyon varlığının Mann-Kendall testinin varyansını artırdığı ortaya çıkmıştır. Bu nedenle, MannKendall yöntemini uygulamadan önce seri içerisindeki otokorelasyon katsayısı belirlenmeli ve seri içerisinden çıkarılması gerekmektedir. $\mathrm{Bu}$ amaçla uygulanan yöntem Prewhitening olarak adlandırılmaktadır. Bu sayede serisel korelasyonun I. Tip hatalarının oluşumu üzerindeki etkisi ortadan kaldırılmaktadır (Blain, 2012; Von Storch ve Navarra, 1995; Yue ve Wang, 2002). Fakat bu yöntem otokorelasyonu kaldırırken trendin de bir kısmını kaldırabileceğinden II. Tip hatalarının ortaya çıkmasında bir artışa da neden olabilmektedir (Fleming ve Clark, 2002; Yue ve Wang, 2002). Yue ve Wang (2002), serisel korelasyon ile doğrusal trend arasındaki ilişkiyi araştırmıştır ve lag 1 otokorelasyon katsayısını belirlemeden önce seri içerisinden trendin eğiminin çıkarılmasının gerçek seri korelasyonunun belirlenmesine önemli derecede katkı sağladığ1 sonucuna varmıştır. Bunun üzerine Trend-Free Prewhitening yöntemini geliştirmiştir. $\mathrm{Bu}$ çalışmada, öncelikle serisel korelasyondan arındırılmamıs ZTD zaman serisine trend analizi yapmak ardından ZTD zaman serilerindeki serisel korelasyon varlı̆̆ını araştırıp ortaya çıkan serisel korelasyonu gidererek veriye uygulanan MannKendall testi sonucunda trendin varlığında değişim olup olmadığını belirlemek amaçlanmıştır. Serisel korelasyon varlığını test etmek için otokorelasyon katsayısı hesaplanmıştır. Veriyi serisel korelasyondan arındırmak için TrendPrewhitening yöntemi uygulanmış olup tekrar Mann-Kendall testi yapılarak serisel korelasyonun trend belirleme üzerindeki etkisi belirlenmiştir. Böylece Trend-Free Prewhitening yönteminin trendin belirlenmesi üzerindeki etkisi de görülmeye çalış1lmıştır.

\section{Yöntem}

\subsection{Mann-Kendall Testi ile Trend Analizi}

Mann-Kendall testi, hidroloji ve klimatoloji gibi alanlarda zaman serilerindeki trendin 
belirlenmesinde sıklıkla kullanılan ve Dünya Meteoroloji Örgütü (WMO-World Meteorological Organization) tarafindan da önerilen parametrik olmayan trend analizi yöntemlerinden biridir. Yöntemde uygulanan hipotez testi ile trend varlığ araştırılmaktadır. Bu testte hipotezler;

- $\mathrm{H}_{0}$ hipotezi: "Zamana bağll olarak stralanmiş $\left(x_{1}, x_{2}, \ldots, x_{n}\right)$ gözlem değerleri zamandan bağımsız ve benzer dăğlıml rasgele değişkenlerdir."

- $\mathrm{H}_{1}$ hipotezi: “ $(k \neq j)$ olmak üzere $(k, j \leq n)$ için seri içerisinde $x_{k}$ ve $x_{j}$ değerlerinin dağılımı benzer değildir."

şeklinde kurulur. Mann-Kendall test değeri ise,

$S=\sum_{k=1}^{n-1} \sum_{j=k+1}^{n} \operatorname{sgn}\left(x_{j}-x_{k}\right)$

şeklinde hesaplanır. Burada; $n$, ölçü sayısı olup sgn işaret fonksiyonudur. Test, $x_{k}(k=1, \ldots, n-$ 1) veri setine ve $x_{j}(j=i+1, \ldots, n)$ veri setine uygulanır, sgn işaret fonksiyonu değeri $x_{j}$ ve $x_{k}$ değerlerinin

$\operatorname{sgn}\left(x_{j}-x_{k}\right)=\left\{\begin{array}{c}1 ; x_{j}>x_{k} \\ 0 ; x_{j}=x_{k} \\ -1 ; x_{j}<x_{k}\end{array}\right.$

şeklinde kıyaslanması ile elde edilir. S'nin varyans1 ise,

$\operatorname{Var}(S)=\frac{n(n-1)(2 n+5)}{18}$

şeklinde bulunur. Eğer seri içerisinde aynı değere sahip veriler varsa varyans hesabı Eşitlik (4)'e göre yapılır.

$\operatorname{Var}(S)=\frac{n(n-1)(2 n+5)-\sum_{i=1}^{k} t_{i}\left(t_{i}-1\right)\left(2 t_{i}+5\right)}{18}$

Burada; $k$, veri setindeki bağıl grupların sayısı, $t_{i}$ değeri ise $i$ uzunluğundaki bir seride bağlı gözlemleri ifade etmektedir. Standartlaştırılmış Mann-Kendall istatistiği $Z$,

$Z=\left\{\begin{array}{r}\frac{S-1}{\sqrt{\operatorname{Var}(S)}} ; S>0 \\ 0 ; S=0 \\ \frac{S+1}{\sqrt{\operatorname{Var}(S)}} ; S<0\end{array}\right.$

şeklindedir. Burada, \%95 istatistik güvenle $\left(\mathrm{Z}_{1-\alpha / 2}\right)$ bulunan standart normal dağılım tablo değeri $\left(Z_{\text {tablo }}\right)$ ile $Z$ Mann-Kendall test değeri karşılaştırılır. Eğer $|\mathrm{Z}|<\mathrm{Z}_{\text {tablo }}$ ise $\mathrm{H}_{0}$ hipotezi kabul edilir. Tersi durumda $\mathrm{H}_{0}$ hipotezi reddedilir.
$\mathrm{Bu}$ durumda trend olduğu sonucuna varılır. $S$ değeri pozitif ise trendin artan yönde olduğu, negatif ise azalan yönde olduğuna karar verilir (Mann 1945, Kendall 1975).

\subsection{Serisel Korelasyon (Otokorelasyon)}

Otokorelasyon veya serisel korelasyon, gözlemlenen değerler arasındaki benzerliğin zamansal gecikmenin bir fonksiyonu olarak ifade edilmesidir (URL-2, 2017). Seri değerlerinden hesaplanarak elde edilen otokorelasyon katsayıları farklı zaman değerlerindeki gözlem değerleri arasındaki ilişkiyi gösteren katsayılardır. $\mathrm{Bu}$ katsayılar, zaman serilerinin sahip olduğu özelliklerin önemli bir göstergesidir ve bir serinin komşu değerleri ile arasındaki bağımlılığın derecesini ortaya koymaktadır (Akgül, 2003). Zaman serilerindeki iç bağımlılık otokorelasyon katsayıları ile ölçülebilmektedir. Eğer, zaman serisinde serisel bir korelasyon mevcut ise trend analizi yapılmadan önce giderilmesi gerekmektedir. Aksi halde, seride trend yokken, trendin var olduğu sonucu ortaya çıkabilmektedir veya zayıf trend eğilimlerinin belirlenememesi olabilmektedir. Bunu belirlemek için önce karalıklı otokorelasyon katsayısı hesaplanmaktadır.

$r_{k}=\frac{\sum_{i=1}^{n-k}\left(x_{i}-\bar{x}\right)\left(x_{i+k}-\bar{x}\right)}{\sum_{i=1}^{n}\left(x_{i}-\bar{x}\right)^{2}}, k=1,2, \ldots$

Burada; $x_{i}$, zaman serisi verileri, $n$ ise veri sayıs1, $k$ ise aralıktır. $r_{k}, 0 \leq \mathrm{r}_{\mathrm{k}} \leq 1$ arasında değerler almaktadır. "0" zaman serisinin bağımsız olduğu, "1" ise zaman serisinde otokorelasyon olduğu anlamına gelmektedir. Otokorelasyon katsayıs1, Dünya Meteoroloji Örgütü tarafindan önerilen $\% 95$ anlamlılık seviyesinde yapılan tek yönlü hipotez testi ile test edilmektedir (Olofintoye vd, 2012).

$r_{k}(\% 95)=\frac{-1+1.645 \sqrt{n-k-1}}{n-k}$

Eğer elde edilen korelasyon katsayısı $\left(r_{k}\right), \% 95$ istatistik güvenle hesaplanan kritik değerden $\left(\mathrm{r}_{\mathrm{k}}(\% 95)\right)$ büyükse zaman serisinin içerisinde serisel bir korelasyon olduğu sonucuna varılmaktadır. $\mathrm{Bu}$ durumda, serisel korelasyonun seri içerisinden çıkarılması gerekmektedir.

\subsection{Trend Free Prewhitening Yöntemi}

Zaman serilerindeki pozitif serisel korelasyon parametrik olmayan testlerle trendin belirlenmesini olumsuz etkilemektedir (Kulkarni ve Von Storch 1995). Bu nedenle, verinin serisel 
korelasyondan arındırılması gerekmektedir. Trend-Free Prewhitening (TFPW) yöntemi, Yue ve Wang (2002), Yue vd. (2003) tarafindan lineer trend bileşeni ve AR(1) (Autoregressive Process) bileşeni arasındaki ters etkileşiminin üstesinden gelmek için ortaya çıkarılmıştır. Yönteme göre,

1. lag 1 otokorelasyon katsayıs1 $\left(\mathrm{r}_{1}\right)$;

$r_{k}=\frac{\sum_{i=1}^{n-k}\left(x_{i}-\bar{x}\right)\left(x_{i+k}-\bar{x}\right)}{\sum_{i=1}^{n}\left(x_{i}-\bar{x}\right)^{2}}$

olarak hesaplanır. Burada; $x$, veri, $\bar{x}$, verilerin ortalaması, $k$, aralığ 1 ifade etmektedir.

2. Hesaplanan otokorelasyon katsayısının anlamlılı̆̆

$\frac{-1-1.645 \sqrt{N-k-1}}{N-k} \leq r_{k} \leq \frac{-1+1.645 \sqrt{N-k-1}}{N-k}$

ile test edilir. Eğer otokorelasyon katsayısı Eşitlik (9) da belirtilen aralıkta ise $\% 95$ istatistik güvenle serinin bağımsız olduğu ve trend-free prewhitening yapılması gerekmediği sonucuna varılır. Tersi durumda verilerin bağımlı olduğu kabul edilerek Mann-Kendall testini uygulamadan önce Trend-Free Prewhitening uygulanır.

3. Trendi modellemek için,

$y=a_{0}+a_{1} x$

regresyon modeli oluşturulur. Burada; $y$, zamana bağlı değişimi ifade eden veriler, $x$, bağımsız değişken, $a_{1}$, eğim, $a_{0}$, kesişim sabitini ifade etmektedir. Burada $a_{1}, x$ trend bileşenidir ve;

$y_{i}^{\prime}=y_{i}-a_{1} x_{i}$

olarak seriden çıkarılır.
4. Eşitlik (8) kullanılarak trendden arındırılmış seri için lag 1 otokorelasyon katsayısı hesaplanır.

5. Trendden arındırılmış seriden serisel korelasyonun etkisi;

$y_{i}^{\prime \prime}=y_{i}^{\prime}-r_{1} * y_{i-1}^{\prime}$

ile giderilir.

6. Elde edilen seriye trend tekrar eklenerek serisel korelasyondan arındırılmış yeni bir seri;

$y_{i}^{\prime \prime \prime}=y_{i}^{\prime \prime}+a_{1} x_{i}$

olarak elde edilir. Mann-Kendall testi elde edilmiş olan $y_{i}^{\prime \prime \prime}$ serisine tekrar uygulanır. Trend-Free Prewhitening yöntemi, yapılan trend analizinin istatistiksel öneminin daha iyi tahmin edilmesini sağlamaktadır (Adib vd. 2017; Wang vd. 2015).

\section{Uygulama}

$\mathrm{Bu}$ çalışmada, Türkiye'den ANKR istasyonu, Avrupa'dan BRUS (Belçika), GRAS (Fransa), LAMA (Polonya), MAS1 (İspanya), MATE (İtalya), PENC (Macaristan), WTZR (Almanya), ONSA (İsveç) ve SVTL (Rusya) istasyonları olmak üzere toplam 10 tane IGS istasyonunda (Şekil 1) (Tablo 1) 1995-2010 y1llarına ait verilerin analizi ile elde edilmiş ZTD ürünlerinin COST Aksiyonu ES1206, GNSS4SWEC kapsamında Dr. Olivier Bock (IGN, Fransa) tarafından yeniden hesaplanmış (IGS Repro1) ZTD zaman serileri kullanılmıştır (URL-1, 2017). Zaman serilerinde trend ve serisel korelasyon etkilerini incelemek amaciyla seçilen yöntemlerin uygulanması için MATLAB ortamında kodlar yazılmıştır.

Tablo 1. İstasyon bilgileri

\begin{tabular}{|l|l|l|l|l|}
\hline IGS İstasyon Kodu & Ülke & Enlem (derece) & Boylam (derece) & Yükseklik $(\mathrm{m})$ \\
\hline ANKR & Türkiye & 39.8875 & 32.7583 & 974.8 \\
\hline BRUS & Belçika & 50.7980 & 4.3583 & 158.3 \\
\hline GRAS & Fransa & 43.7547 & 6.9205 & 1319.3 \\
\hline LAMA & Polonya & 53.8922 & 20.6697 & 187.0 \\
\hline MAS1 & İspanya & 27.7636 & -15.6330 & 197.3 \\
\hline MATE & İtalya & 40.6488 & 16.7044 & 535.6 \\
\hline ONSA & İsveç & 57.3953 & 11.9245 & 44.4 \\
\hline PENC & Macaristan & 52.3791 & 13.0658 & 144.4 \\
\hline SVTL & Rusya & 60.5328 & 29.7808 & 77.1 \\
\hline WTZR & Almanya & 49.1441 & 12.8788 & 666.0 \\
\hline
\end{tabular}




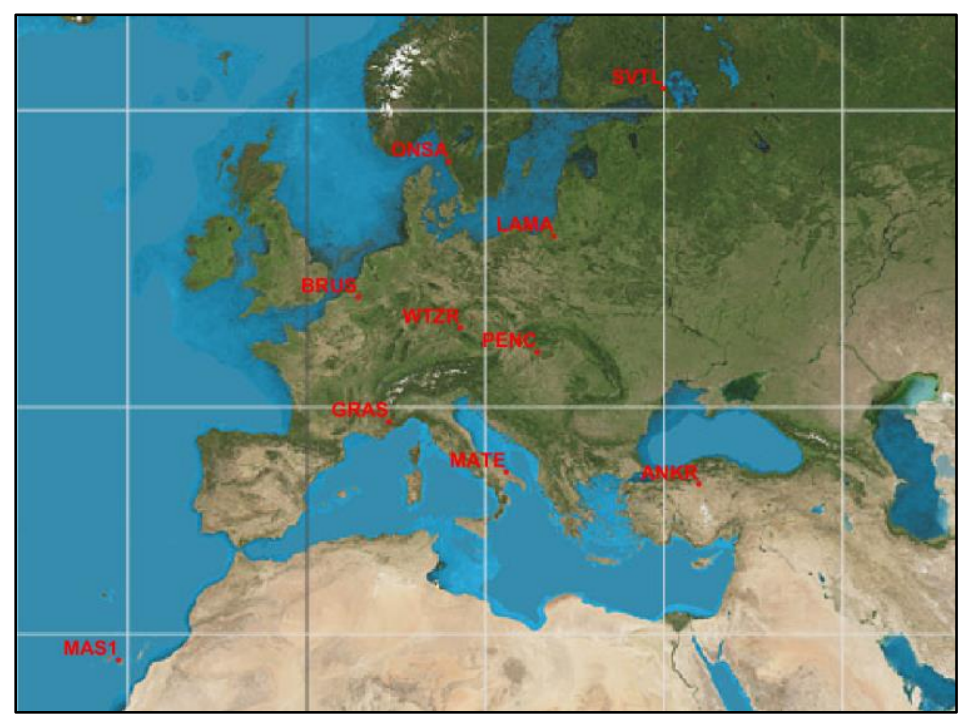

Şekil 1. Çalışmada kullanılan istasyonlar

Parametrik olmayan testlerden biri olan MannKendall testi ile 1995-2010 yılları arasında 10 IGS istasyonu için günlük ZTD verilerinde trend eğilimi belirlenmiştir. $\mathrm{Bu}$ çalışmada kullanılan istasyonlarda aynı değere sahip ZTD verileri bulunması sebebiyle varyans değerleri (4) eşitliği ile hesaplanmıştır. $\mathrm{Bu}$ nedenle öncelikle aynı değere sahip olan veriler MATLAB programlama dilinde yazılan program kodları ile tespit edilmiştir. Mann-Kendall test değeri (Z) bulunduktan sonra $\% 95$ istatistik güvenle standart normal dağılım tablo değeri $\left(\mathrm{Z}_{\text {tablo }}\right)$ elde edilmiştir ve test istatistiği tablo değeri ile karşılaştırılarak trend olup olmadığı tespit edilmiştir. Ardından trendin olduğu istasyonlarda trendin yönü belirlenmiştir. Bu istasyonlarda (1) eşitliğine göre hesaplanan $\mathrm{S}$ değeri pozitif ise artan yönde bir trend, negatif ise azalan yönde bir trend olduğuna karar verilmiştir.

Yapılan Mann-Kendall testi sonucunda, ANKR, MAS1 ve ONSA istasyonlarında artan yönde trend, BRUS ve GRAS istasyonlarında azalan yönde trend, diğer istasyonlarda ise belirgin bir trend belirlenememiştir (Şekil 2).

ZTD verilerine Mann-Kendall testi uygulandiktan sonra serisel korelasyonun Mann-Kendall yöntemi ile trend belirleme üzerindeki etkisini belirlemek için Şekil 3'te belirtilen adımlara göre seri içerisinde korelasyonun etkili olup olmadığı tespit edilip ardından Trend-Free Prewhitening yöntemi uygulanmıştır.
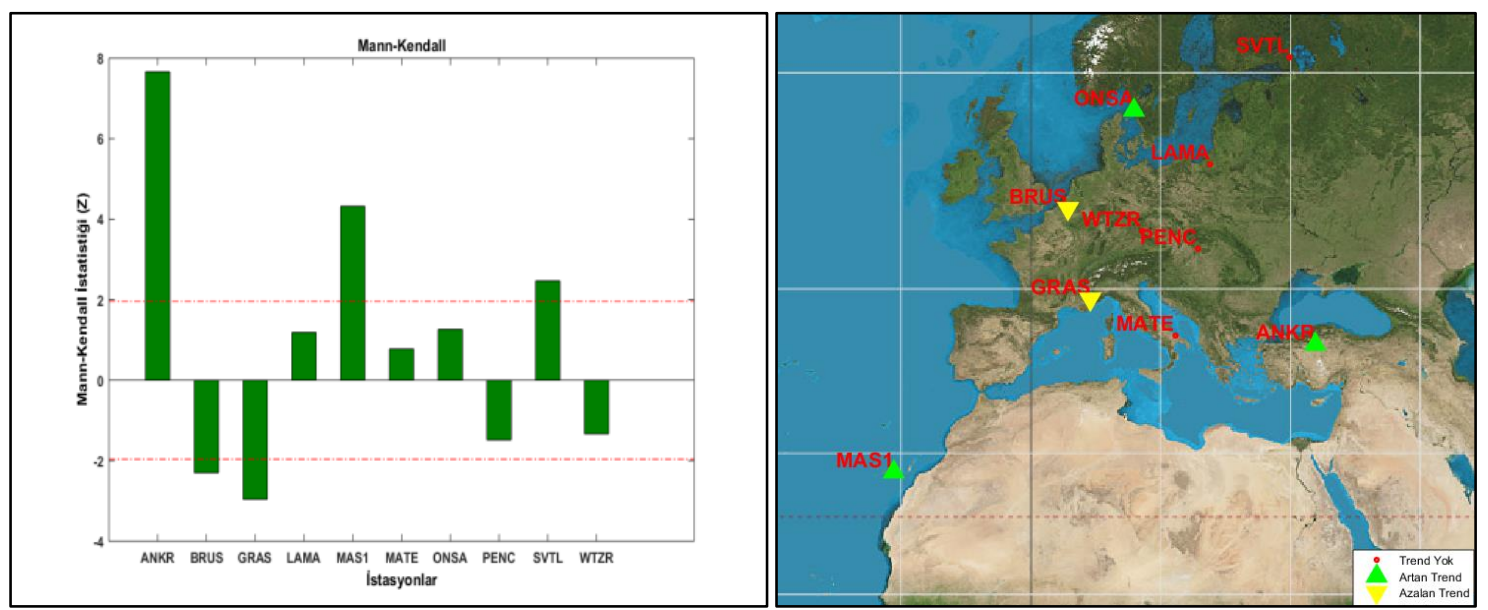

Şekil 2. Serisel korelasyondan arındırılmamış ZTD verileri Mann-Kendall testi sonuçları 


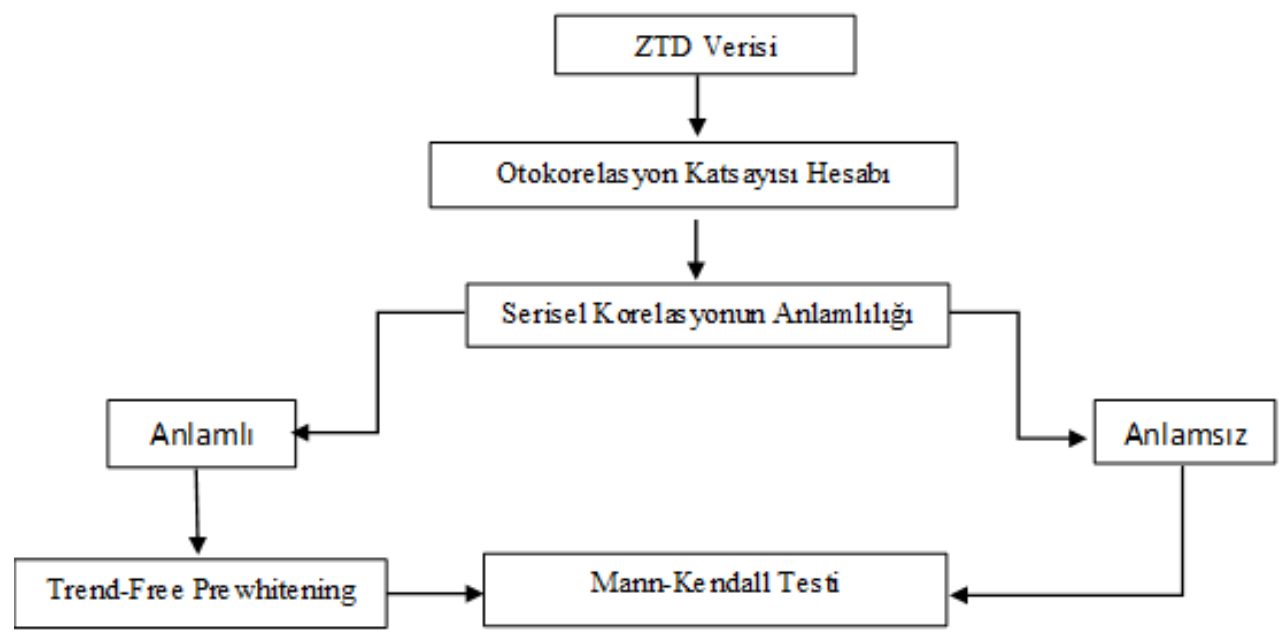

Şekil 3. Serisel korelasyondan arındırma iş akış şeması

Her bir istasyona ait ZTD verilerinde serisel korelasyon olup olmadığına karar verebilmek için (6) eşitliğine göre otokorelasyon katsayısı hesaplanmıştır. Lag 1 için hesaplanan otokorelasyon katsayılarına bakıldığında en büyük değerin $r_{k}=0.8366$ ile SVTL istasyonunda olduğu görülmüştür. En küçük otokorelasyon ise $\mathrm{r}_{\mathrm{k}}=0.6942$ ile GRAS istasyonuna aittir (Şekil 4).

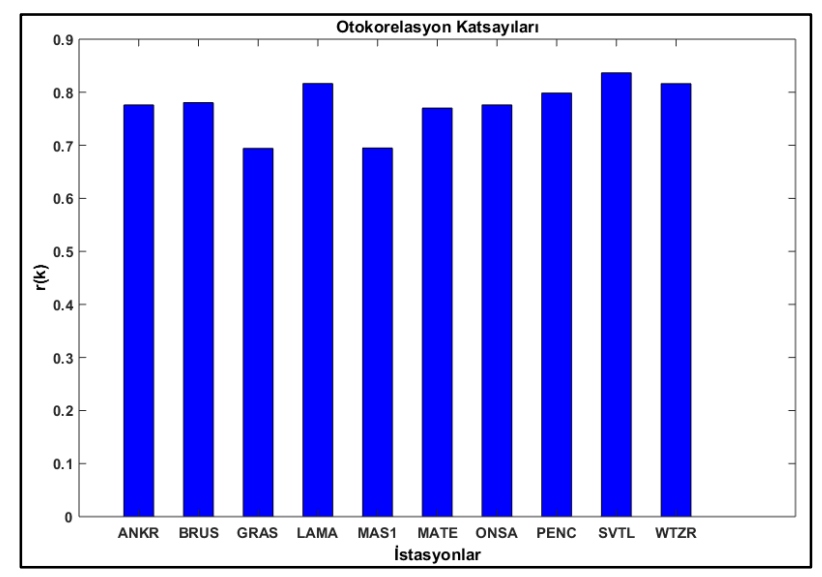

Şekil 4. ZTD istasyonları otokorelasyon katsayıları (trend çıkarılmamış)

Elde edilen otokorelasyon katsayıları ile kritik değer Başlık 1.2 de anlatıldığı gibi karşılaştırıldığında istasyonların tümünde serisel korelasyonun anlamlı olduğu ve Trend-Free Prewhitening yapılması gerektiği sonucuna varılmıştır (Tablo 2).

Serisel korelasyonun çıkarılması gerektiğine karar verildikten sonra ZTD verilerinden korelasyonu çıkarmak için öncelikle (11) eşitliğine göre seriden trend çıkarılmıştır. Ardından tekrar (6) eşitliğine göre lag 1 otokorelasyon katsayısı hesaplanmıştır (Tablo 3).

Tablo 2. ZTD verilerine ait otokorelasyon katsayıları (trend çıkarılmamış)

\begin{tabular}{|l|l|l|}
\hline $\begin{array}{l}\text { İstasyon } \\
\text { Kodu }\end{array}$ & $\begin{array}{l}\text { Otokorelasyon Katsayısı } \\
(\mathbf{k = 1})\end{array}$ & $\begin{array}{l}\text { Kritik Değer } \\
(\boldsymbol{\alpha}=\mathbf{0 . 0 5})\end{array}$ \\
\hline ANKR & 0.7762 & 0.0304 \\
\hline BRUS & 0.7805 & 0.0257 \\
\hline GRAS & 0.6942 & 0.0274 \\
\hline LAMA & 0.8165 & 0.0259 \\
\hline MAS1 & 0.6948 & 0.0261 \\
\hline MATE & 0.7702 & 0.0260 \\
\hline ONSA & 0.776 & 0.0263 \\
\hline PENC & 0.7985 & 0.0264 \\
\hline SVTL & 0.8366 & 0.0264 \\
\hline WTZR & 0.8162 & 0.0259 \\
\hline
\end{tabular}

Tablo 3. ZTD verilerine ait otokorelasyon katsayıları (trend çıkarılmış)

\begin{tabular}{|l|l|l|}
\hline $\begin{array}{l}\text { İstasyon } \\
\text { Kodu }\end{array}$ & $\begin{array}{l}\text { Otokorelasyon Katsayısı } \\
(\mathbf{k = 1})\end{array}$ & $\begin{array}{l}\text { Kritik Değer } \\
(\boldsymbol{\alpha}=\mathbf{0 . 0 5})\end{array}$ \\
\hline ANKR & 0.7713 & 0.0304 \\
\hline BRUS & 0.7802 & 0.0257 \\
\hline GRAS & 0.8211 & 0.0274 \\
\hline LAMA & 0.8349 & 0.0259 \\
\hline MAS1 & 0.7378 & 0.0261 \\
\hline MATE & 0.8017 & 0.0260 \\
\hline ONSA & 0.8132 & 0.0263 \\
\hline PENC & 0.8449 & 0.0264 \\
\hline SVTL & 0.8762 & 0.0264 \\
\hline WTZR & 0.8368 & 0.0259 \\
\hline
\end{tabular}

Trend çıkarıldıktan sonrada hesaplanan otokorelasyon katsayıları kritik değer ile karşılaştırıldığında serisel korelasyonun anlamlı olduğu görülmüsstür. En büyük otokorelasyon katsay1s1 $r_{k}=0.8762$ ile SVTL istasyonunda elde edilmiştir. En küçük otokorelasyon ise $r_{k}=0.7378$ ile MAS1 istasyonuna aittir. (Şekil 5). 


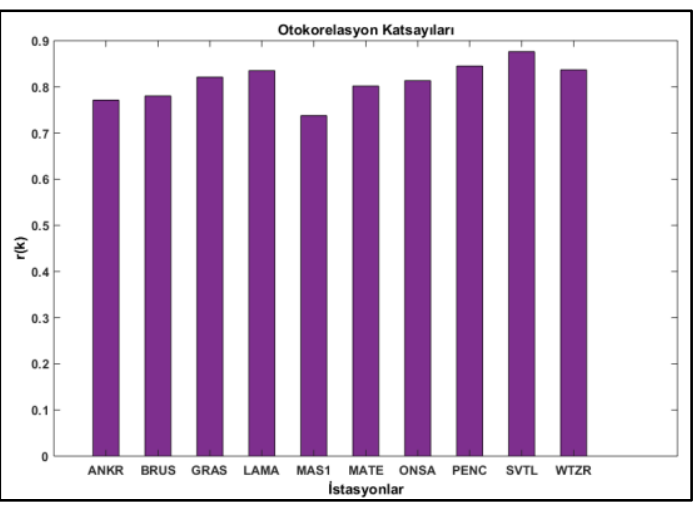

Şekil 5. ZTD istasyonları otokorelasyon katsayıları (trend çıkarılmış).
Ardından (12) eşitliğinde anlatıldığ şekilde serisel korelasyonun etkisi giderilmiştir ve (13) eşitliğine göre tekrar trend eklenerek serisel korelasyondan arındırılmış yeni bir seri elde edilmiştir. $\mathrm{Bu}$ seriden tekrar Başlık 1.1 de anlatıldığ serisel korelasyonun trend belirleme üzerindeki etkisi belirlenmeye çalışılmıştır. Buna göre, ANKR, MAS1, LAMA, ONSA ve SVTL istasyonlarında artan yönde trend, BRUS, GRAS ve PENC istasyonlarında azalan yönde, MATE ve WTZR istasyonlarında ise trend bulunmamıştır (Şekil 6) (Tablo 4).
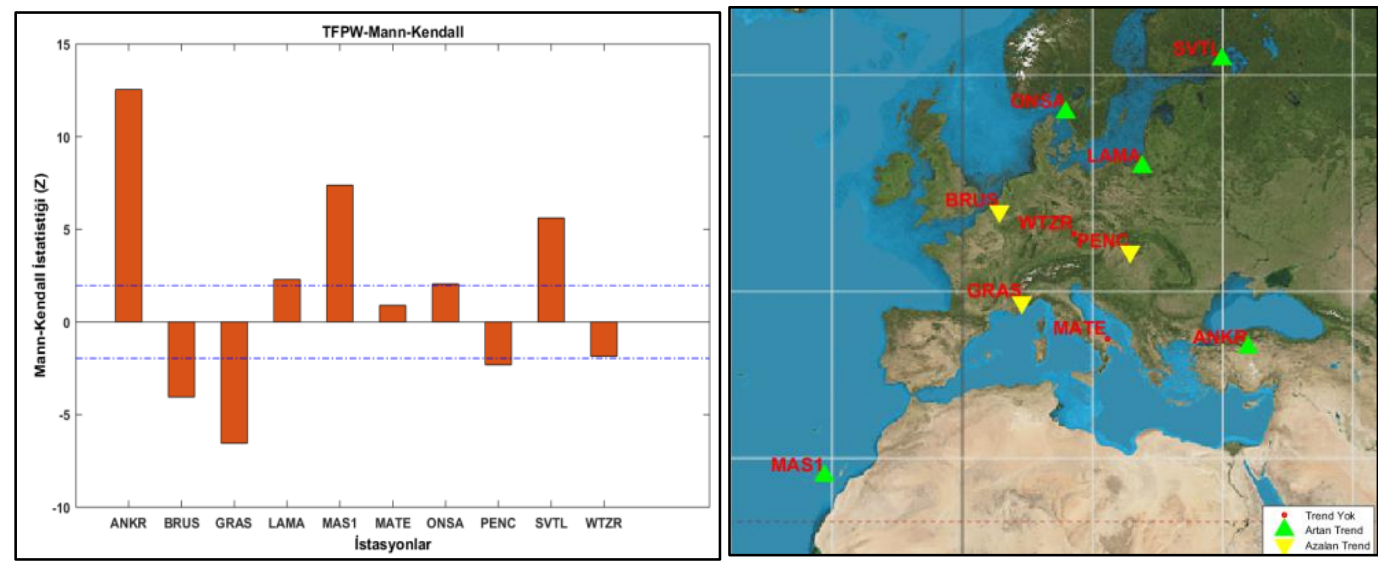

Şekil 6. Serisel korelasyondan arındırılmış ZTD verileri Mann-Kendall testi sonuçları

Tablo 4. TFPW öncesi ve TFPW sonrası Mann-Kendall testi trend sonuçları

\begin{tabular}{|l|l|l|l|l|}
\hline \multirow{2}{*}{} & \multicolumn{2}{|c|}{ TFPW Öncesi } & \multicolumn{2}{c|}{ TFPW Sonrası } \\
\cline { 2 - 5 } & Trend & Trendin Yönü & Trend & Trendin Yönü \\
\hline ANKR & Trend Var & Artan & Trend Var & Artan \\
\hline BRUS & Trend Var & Azalan & Trend Var & Azalan \\
\hline GRAS & Trend Var & Azalan & Trend Var & Azalan \\
\hline LAMA & Trend Yok & - & Trend Var & Artan \\
\hline MAS1 & Trend Var & Artan & Trend Var & Artan \\
\hline MATE & Trend Yok & - & Trend Yok & - \\
\hline ONSA & Trend Yok & - & Trend Var & Artan \\
\hline PENC & Trend Yok & - & Trend Var & Azalan \\
\hline SVTL & Trend Var & Artan & Trend Var & Artan \\
\hline WTZR & Trend Yok & - & Trend Yok & - \\
\hline
\end{tabular}

\section{Sonuçlar}

Uzun dönem ZTD zaman serilerinde trend belirleme iklim çalışmaları için önemlidir. Özellikle doğru trend eğilimlerinin belirlenmesi için seride korelasyonun etkili olup olmadığının tespit edilmesi ve varsa arındırılması önemlidir.

$\mathrm{Bu}$ çalışmada, Türkiye ve Avrupa'dan seçilen çeşitli istasyonlara ait ZTD verileri Trend-Free
Prewhitening yöntemi ile serisel korelasyondan arındırılarak serisel korelasyondan arındırılmadan önceki ve sonraki Mann-Kendall trend analizi sonuçları karşılaştırılmıştır. Serisel korelasyonun trend belirleme üzerindeki etkisi görülmeye çalışılmıştır.

ZTD zaman serilerinde gerçek trend eğilimlerinin belirlenmesi için seri içerisinde korelasyon varlığını araştırmanın ve korelasyon olması 
durumunda seriden çıkarılmasının önemli olduğu görülmüştür. Korelasyondan arındırmanın yapılmadığı durumda, trend eğilimi olmasına rağmen belirlenemediği istasyonlar olmuştur. TFPW öncesi ve TFPW sonrası test sonuçlarına göre, serisel korelasyonun ZTD trend analizinde sonuçları önemli ölçüde etkilediği görülmüştür. Serisel korelasyon nedeniyle küçük trend eğilimi olan LAMA (Polonya), ONSA (İsveç) ve PENC (Macaristan) istasyonlarında TFPW öncesi yapilan Mann-Kendall testinde trend belirlenmemiş olup serisel korelasyonun arındırılması ile LAMA (Polonya) ve ONSA (İsveç) istasyonlarında artan yönde, PENC (Macaristan) istasyonunda azalan yönde trend belirlenmiş̧ir. Diğer istasyonlarda ise değişiklik gözlemlenmemiştir.

Tüm istasyonların trend analizi sonuçlarına bakıldığında, ANKR (Türkiye), LAMA (Polonya), MAS1 (İspanya), ONSA (İsveç) ve SVTL (Rusya) istasyonlarında artan yönde trend; BRUS (Belçika), GRAS (Fransa) ve PENC (Macaristan) istasyonlarında azalan yönde trend tespit edilmiştir. MATE (İtalya) ve WTZR (Almanya) istasyonlarında trend eğilimi belirlenmemiştir. Artan yönde trend belirlenen LAMA, MAS1 ve ONSA istasyonları okyanusa kıyısı olan bir konumda olması nedeniyle nemli bir bölgede bulunmaktadır. $\mathrm{Bu}$ bölgelerde ZTD'nin 1slak bileşeninin etkisinin artmasına bağl1 olarak artan yönde trend bulunduğu düşünülmüştür.

\section{Teşekkür}

IWV verilerini IGS Repro1 ve ERA-Interim'den elde ettiği için Fransa IGN'deki Dr. Olivier BOCK'a teşekkür ederim. $\mathrm{Bu}$ veriler COST Action ES1206, GNSS4SWEC çerçevesinde hazırlanmış ve kalitesi kontrol edilmiştir.

We would like to acknowledge Dr. Olivier BOCK, IGN, France, for making the IWV data from IGS repro1 and ERA-Interim available. These data were prepared and quality checked in the framework of COST Action ES1206, GNSS4SWEC.

\section{Kaynaklar}

Adib A., Kalaee M.M.K., Shoushtari M.M., Khalili K., 2017. Using of Gene Expression Programming and Climatic Data for Forecasting Flow Discharge by Considering Trend, Normality, and Stationarity
Analysis, Arabian Journal of Geosciences, 10: 208, DOI 10.1007/s12517-017-2995-z.

Akgül, I., 2003. Zaman Serilerinin Analizi ve ARIMA Modelleri, Der Yayınevi, İstanbul.

Baldysz, Z., Nykiel, G., Figurski, M., Szafranek, K. ve Kroszczyński, K., 2015. Investigation of the 16-year and 18-year ZTD Time Series Derived from GPS Data Processing, Acta Geophysica, 1103-1125.

Baldysz, Z., Nykiel, G., Araszkiewicz, A., Figurski, M., and Szafranek, K., 2016. Comparison of GPS Tropospheric Delays Derived from Two Consecutive EPN Reprocessing Campaigns from the Point of View of Climate Monitoring, Atmos. Meas.Tech. Discuss., doi:10.5194/amt2016-5, 1.

Beşel C., 2017. IGS İstasyonları Zenit Troposferik Gecikme Parametresi Zaman Serilerinde Trend ve Mevsimsel Etki Analizleri, Yüksek Lisans Tezi, Karadeniz Teknik Üniversitesi, Fen Bilimleri Enstitüsü, Trabzon.

Bevis, M., Businger, S., Herring, T.A., Rocken, C., Anthes, R.A. ve Ware, R.H., 1992. GPS Meteorology: Remote Sensing of Atmospheric Water Vapour Using the Global Positining System, Journal of Geophysical Research, 97, D14, 1578715801.

Blain, G.C., 2012. Revisiting the Probabilistic Definition of Drought: Strengths, Limitations and an Agrometeorological Adaptation, Bragantia, 71, 1,132-141.

Blain G.C.,2015. The Influence of Nonlinear Trends on the Power of the Trend-Free PreWhitening Approach, Acta Scientiarum. Agronomy,37, 1, 21-28, DOI 10.4025/actasciagron.v37i1.18199.

COST, 2012. Memorandum of Understanding for the Implementation of a European Concerted Research Action, COST Action ES1206, Advanced Global Navigation Satellite Systems Tropospheric Products for Monitoring Severe Weather Events And Climate (GNSS4SWEC), European Cooperation in Science and Technology. 
Fleming, S.W ve Clarke, G.K.C., 2002. Autoregressive Noise, Deserialization, and Trend Detection and Quantification in Annual River Discharge Time Series, Canadian Water Resources Journal, 27, n. 3, p. 335-354.

Guerova, G., 2013. Ground-Based GNSS Meteorology, Gfg Summer School, Potsdam, Almanya.

Hamed, K.H. ve Rao, A.R.A., 1998. Modified Mann-Kendall Trend Test for Autocorrelated Data, J. Hydrol., 204,182196.

Kendall, M.G., 1975. Rank Correlation Methods, Charles Griffin, London.

Kulkarni A. ve Von Storch H., 1995. Monte Carlo Experiments on the Effect of Serial Correlation on the Mann-Kendall Test of Trend, Meteorologische Zeitschrift, 4(2):82-85.

Mann, H.B, 1945. Non-Parametric Tests Aganist Trend, The Econ. Society, 3, 245-259.

Olofintoye, O., Adeyemo, J., ve Otieno, F., 2012. Impact of Regional Climate Change on Freshwater Resources and Operation of the Vanderkloof Dam System in South Africa, Global Warming-Impact and Future Perspective, doi: 10.5772/50414 165-184.

Rocken C., Hove T.V., Johnson J., Solheim F., Ware R., Bevis M., Chiswell S. ve Businger S., 1994. GPS/STORM-GPS Sensing of Atmosferic Water Vapor for Meteorology, Journal of Atmospheric and Oceanic Technology, 12, 468-478.

Jin, S., Park, J., Cho, J. ve Park, P., 2007. Seasonal Variability of GPS-Derived Zenith Tropospheric Delay (1994-2006) and Climate Implications, Journal of
Geophysical Research, 112, D09110, doi:10.1029/2006JD007772.

Tanır Kayıkçı E. ve Beşel C., 2017. Trend Analysis of The Zenith Tropospheric Delay Time Series, Proceedings, International Symposium on GIS Applications in Geography and Geosciences, 445-455.

Von Storch H. ve Navarra A., 1995. Analysis of Climate Variability, Applications of Statistical Techniques, Springer, Berlin.

Wang W., Chen Y., Becker S. and Liu B., 2015. Linear Trend Detection in Serially Dependent Hydrometeorological Data Based on a Variance Correction Spearman Rho Method, Water 7(12):7045-7065, DOI 10.3390/w7126673.

URL-1: https://doi.org/10.14768/06337394-73a9407c-9997-0e380dac5590. Aralık 2017.

URL-2

https://tr.wikipedia.org/wiki/Otokorelasyon. 25 Ocak 2017.

Yong, W., Binyun, Y., Debao, W. ve Yanping, L., 2008. Zenith Tropospheric Delay from GPS Monitoring Climate Change of Chinese Mainland, Education Technology and Training, 2008 and 2008 International Workshop on Geoscience and Remote Sensing, ETT and GRS 2008, International Workshop on, 1, doi: 10.1109/ETTandGRS.2008.43.

Yue S. ve Wang C., 2002. Applicability of Prewhitening to Eliminate the Influence of Serial Correlation on the Mann-Kendall Test, Water Resour Res 38(6):41-47.

Yue, S., Pilon, P. ve Phinney, B., 2003. Canadian Streamflow Trend Detection: Impacts of Serial and Cross-Correlation, Hydrogical, Sciences Journal, 48,1,51-64. 